\title{
Disaster Management, Resilience of System and Space Information Technologies
}

\author{
Maksym Sokiran \\ Ph.D. in Law, Scientific and Research Institute of Public Law (Kyiv, Ukraine) \\ E-mail: maxim.sokiran@gmail.com \\ https://orcid.org/0000-0002-1682-2012
}

The quantity of natural disasters is constantly growing; it is becoming increasingly difficult to overcome their consequences. The resilience of the system is constantly checked for durability, so it is important to understand how to manage natural disasters. The use of spacebased information technologies, such as satellite systems of Earth 's observation, meteorology, navigation and telecommunications, plays a significant role for in the disaster prevention and response as well as in strengthening sustainable development. The author analyzes the international and national legal and regulatory framework, the existing scientific challenges on this issue. The article is devoted to the study of various international initiatives for the use of information obtained through space activities for the purpose of prevention, mitigation and relief operations. The article defines the concept of "system resilience" and the role of space information technology to manage natural disasters and to strengthen the sustainability of the world community and regions.

Keywords: space, management, system resilience, disasters, natural disasters, space meteorology, satellite telecommunication and navigation systems, Outer Space Treaty.

Received: February 6, 2019; accepted: March 10, 2019

Advanced Space Law, Volume 3, 2019: 120-130.

https://doi.org/10.29202/asl/2019/3/10

\section{Introduction}

Despite the importance of space information technologies for disaster management and the participation of a number of national and international organizations in promoting the use of space for disaster management, this is still a relatively unknown area. Members of academic community, industry, government and wide audience could benefit from bridging this gap and developing knowledge of how space technology is used to prepare, respond and recover from disasters.

Every year, people and communities throughout the Earth are suffering from disasters and severe destructions. This can be either the result of devastating weather conditions such

(C) Sokiran, Maksym, 2019 
as hurricanes, tornadoes, floods, or the result of a significant industry breakdown or large employer's closure. These may be caused by outbreaks of infectious diseases, terrorist attacks, technological failures, or financial crisis as well. The financial, social and environmental consequences of these disasters continue to increase and form a substantial cost for the governments of different countries, as well as for businesses, communities and nations in general.

The role of space information technologies in observing the variability of nature and changes in the Earth system has increased substantially over the past few decades. From the time when the Earth became able to be observed, it became possible to change the global concepts of many variables, which enabled humanity to study fundamentally: the atmosphere, oceanic and land areas, including ozone, clouds, precipitation, sea surface, topography, changes in polar ice masses and changes on the surface. Indeed, with some satellite observations, which have already lasted for more than 40 years, the value of this information for climate monitoring is becoming increasingly apparent. However, much still remains to be done [Strategy, 2013].

The purpose of the article is to raise awareness of space information technologies' contribution to the disaster management during its entire cycle.

\section{Statement of the content}

Before elaborating on the main points of disaster management and the role of space information technologies for the system resilience, it is necessary to analyze the concept of "system resilience".

The term "resilience" is used by many sciences such as ecology, geography, engineering, economics, psychology, sociology, etc.

Judith Rodin, President of the Rockefeller Foundation, describes resilience as a state of system providing wide opportunities to resume work, reducing the suffering of loss or even collapse; as something to which a heightened attention must be paid; since it is no longer possible to ignore the existing threats and afford to use a large amount of resources for recovery from natural disasters that could be prevented or reacted more effectively [Rodin, 2014: 6].

That is, today it is vital to understand the meaning of resilience to the human community. Resilience or lack of it is a complex and dynamic feature of communities and regions. This is a process and a result that requires us to anticipate threats, reduce vulnerability, mobilize our resources and assets and plan a better future.

Analyzing various definitions allows reaching an understanding that today there are three main ways of defining the concept of resilience [Martin \& Sunley, 2015]. They are not mutually exclusive ideas and, in fact, they all can be used simultaneously.

1. Recoverable balance - resilience as a "rebound" or "engineering stability", when, after a shock, the system (community or region) returns to a state that existed before the impact or continues to exist, paying no attention to the impact. Thus, the resilience of the system makes it possible, after a disaster, to quickly restore everything (infrastructure, services, etc.) to their normal operation. The focus of this idea is efficiency, consistency, and predictability of systems.

This definition of resilience has many modifications (resilience of the vessel, weather conditions, aircraft, etc.). The sections of mathematics (the theory of differential equations) and theoretical mechanics are devoted to the study of natural resilience. 
For example, in the theory of an automatic control system, the concept of resilience is connected with its ability to return (with a certain accuracy) to a state of equilibrium after the disappearance of external forces that brought it out of this state [Besekersky \& Popov, 1972]. In general, the resilience of objects is their ability to maintain the current state in the presence of external influences.

2. Resistance - in relation to natural phenomena and economic system, where the concepts of "resilience" and "non-resilience" are considered as antipode concepts. Thus, non-resilience is opposite to resilience, for example, any violation of the steady state of the economy.

In economic theory, the concept of "resilience" of the economy and economic facilities is comprehensive. Economic encyclopedias and dictionaries provide different options for applying the concept of "resistance" to various phenomena. For example, economic dictionaries describe the concepts of "price resilience", "enterprise resilience", and "money circulation resilience". In other words, resilience is considered as a quality and characteristic of different objects. The economy of particular state is considered to be resilient when it successfully opposes adverse fluctuations in world prices, the shadow economy, etc. [Methodological, 2013].

Thus, resilience is a state of a system when resistance is possible, in our opinion, not only to the aggressive effects of the external environment but also to internal adverse development factors. For example, the resilience of the human body to the flu virus, colds, etc.

3. Resilience as "the ability to absorb shocks", also known as "environmental resilience", is the ability of a system that continues to function after a disaster, even if its structure and organization may change. In such a case, the system advances to another level of equilibrium. The resilience of an ecosystem means its ability to return to its original position after the system has been brought out of equilibrium: the more complex the ecosystem is, the more stable it is.

Thus, a resilient equilibrium is understood as the ability of a self-regulating system to return to its original state, at least after a slight deviation.

The Community and Regional Resilience Institute recommends the following definition of community resilience - the ability to anticipate risk, limit its impact, and quickly recover through adaptability and evolution [Community, 2019].

As it was expected, today there is no single definition of the term "system resilience" both in science and in practice.

Taking into account the previously mentioned definitions proposed by the authors, we define the system resilience as an integral and dynamic attribute of the community, which includes the ability of the system to anticipate, control adverse impacts and consequences, adapt and achieve positive results after disasters.

\section{Integration of space information technologies into disaster preparedness and mitigation of its consequences}

Space information technologies are becoming increasingly vital for modern disaster management activities. These technologies primarily include:

- Earth observation satellites (EOS) providing images that help to manage natural disasters quickly by reducing potential risks in a particular area, preparing for possible consequences of a disaster, responding immediately to a disaster itself and recovering thereafter; 
- Global Navigation Satellite Systems (GNSS), for example, the Global Positioning System (GPS), helps to provide accurate position and navigation data, manage infrastructure; rescue teams, allowing them to coordinate their search work;

- Satellite communication (SATCOM) allows data (voice, images, maps, video) to be transmitted when general communication infrastructures are disabled due to the consequences of a disaster. Emergency communications through the semi-mobile terminals and portable satellite phones are especially useful for quick-reaction actions, including damage assessment, search and rescue, news reporting, help coordination and telemedicine actions;

- remote sensing of the Earth and space allows collecting information about an object or space at a distance. The activity on remote sensing of the Earth is aimed at identifying various natural anomalies in order to further use of the collected information to prevent and localize such anomalies.

\section{Legal framework for the use of space information technologies}

The United Nations promotes the use of outer space for peaceful purposes and sharing of the benefits of this space activity by all states.

The main UN intergovernmental body active in this area is the Committee on the Peaceful Uses of Outer Space, established by the General Assembly in 1959 and consisting of 92 UN member states. The Committee analyzes the scope of international cooperation in the peaceful use of outer space, develops programs and directs UN technical cooperation in this area, promotes research and dissemination of information, and also contributes to the development of international space law.

The committee consists of two subcommittees:

- The Scientific and Technical Subcommittee is the coordinator of international cooperation in space research and technology;

- The Legal Subcommittee is working on the development of legal instruments related to rapid technological development in the field of development of outer space.

The Committee and both subcommittees hold annual meetings to discuss the questions submitted to them by the General Assembly, the reports referred to them, and the issues raised by Member States.

The activities of the Committee and its Legal Subcommittee allowed the General Assembly to adopt five legal documents that are still in force and which govern international cooperation in space exploration:

Based on the activity of the Committee and its Legal Subcommittee, the General Assembly also developed the following principles for conducting space activities:

- The Principles Governing the Use by States of Artificial Earth Satellites for International Direct Television Broadcasting (1982) recognize that such use has international political, economic, social and cultural implications. Such activities should promote the free flow of information and knowledge with due respect for the sovereign rights of States, including the principle of non-intervention.

- The Principles Relating to Remote Sensing of the Earth from Outer Space (1986) state that such activities should be carried out for the benefit and in the interests of all states with the indispensable respect for the sovereignty of all states and peoples over their natural resources, as well as the rights and interests of other states. Remote 
sensing should be used to protect the environment and reduce damage from natural disasters.

- The Principles Relevant to the Use of Nuclear Power Sources in Outer Space (1992) confirm that such sources are indispensable for carrying out certain flights into outer space, but their application must be based on careful security. These principles also define the main criteria for the safe use of nuclear energy sources and warning of a space object malfunction when there is a risk of the return of radioactive material to the Earth's surface.

- The Declaration on International Cooperation in the Exploration and Use of Outer Space for the Benefit and in the Interest of All States, Taking into Particular Account the Needs of Developing Countries (1996), provide that states are free to determine all aspects of their participation in international cooperation in the exploration and use of outer space on a fair and a mutually acceptable basis and that such cooperation should be fully consistent with the legitimate rights and interests of the parties concerned.

Thanks to its unique mandate and central role in international cooperation on the use of outer space for peaceful purposes and the global management of space activities, the Committee made a significant contribution to the organization of the first three United Nations conferences on the development and peaceful uses of outer space, held in 1968, 1982 and 1999.

The adoption of these principles by the UN General Assembly promoted the legal regulation of activities in the use of space-based information technologies in disaster management for the sustainable development of mankind.

\section{Disaster management}

Climate change is considered as one of the main challenges of our time and a common problem that negatively affects all regions of the world as a result of numerous processes, in particular global warming, reduction of sea ice, sea level rise, changes in the system of large currents and such extreme weather phenomena as hurricanes, cyclones, tsunamis, droughts, floods, etc.

The development of space information technologies, the constant improvement of technical advances in this area require relevant legal regulation. That is why certain decisions of the UN General Assembly are so important both in the use of space and in the disaster management.

In addition to the above-stated norms and principles governing the use of outer space and technology, the UN General Assembly also adopted a number of legal acts dealing with the disaster management. In particular, International Framework for Action for the International Decade for Natural Disaster Reduction (1989), Yokohama Strategy for a Safer World (1994) and the International Strategy for Disaster Reduction (1999), Hyogo Framework for Action 2005-2015.

In order to successfully implement all these decisions, in 1999 the UN created the Office for Disaster Risk Reduction and authorized it with the UN General Assembly Resolution $(56 / 195)[\mathrm{A} / \mathrm{RES} / 56 / 195,2002]$ to act as the coordinating body in the United Nations system for disaster risk reduction.

International documents define disaster as a massive disruption of social functioning that leads to far-reaching consequences for humans, the environment, the economy and infrastructure. In most cases, natural disasters are caused by nature, but they can also have human causes. Disaster management is the process by which people prepare to respond and learn from the consequences of these emergencies [Subbarao et al., 2014]. 
There is a significant difference between the terms disaster and emergency. While an emergency is an incident that can be handled with local resources, the effects of natural disasters exceed the capabilities of local rescuers. If an event is declared a "disaster", it is required broader or even foreign assistance to deal with the consequences.

The disaster management process can usually be divided into three parts:

1. Early warning (if the event is predictable). This involves the evacuation of people and mobile property to a relatively safe place.

2. Disaster aid. This is the most important step, which consists of organizing aid camps and the provision of food, medicine and other materials.

3. Rehabilitation or provision of basic services to victims for the restoration of living conditions until the situation normalizes.

Despite all the efforts made by the international community, disasters continue to cause significant damage and undermine well-being and threaten the safety of people, communities and entire countries. According to the available data, in all states the level of exposure of the population and physical assets increased faster than vulnerability decreased, creating new risks and causing a steady increase in damage from disasters with significant economic, social, health, cultural and environmental consequences in the short, medium and long term, especially at local and community levels. Recurring small-scale disasters and adverse processes of delayed action primarily affect communities, households, and small and mediumsized enterprises, and they are suffered from a significant proportion of all losses. All states, especially developing states, in which mortality and economic damage from disasters are disproportionately high, face higher levels of possible hidden losses and are experiencing the increasing difficulties in meeting financial and other obligations. In order to solve the problem of disasters, the international community adopted the Sendai Framework for Disaster Risk Reduction 2015-2030 at the Third United Nations World Conference on Disaster Risk Reduction in March 2015 in Japan [Sendai, 2015]. The Sendai Framework Program continued the Hyogo Framework for Action 2005-2015 [Hyogo, 2005].

The Sendai Program outlines four priority areas for preventing new and reducing existing disaster risks: 1) understanding disaster risk; 2) improving the institutional framework for disaster risk management; 3 ) investing in disaster risk reduction measures to strengthen resilience; 4) enhancing disaster preparedness to ensure an effective response and the introduction of the "do better than before" principle in recovery, rehabilitation and reconstruction activities

While the UN member states are developing national and local disaster risk reduction strategies to be adopted by 2020 - a key goal and deadline for implementing the Sendai priorities - the UN continues to work with the parties concerned around the world to promote the use of space information technology for the common welfare. On May 13-15, 2019, the Sixth Session of the UN Office for Disaster Risk Reduction, entitled "Global Platform for Disaster Risk Reduction", was held in Geneva. At the opening of this event Federal Chancellor of the Federal Department of Foreign Affairs of the Swiss Confederation noted in his opening statement that in addition to existing global problems, this century is characterized by unprecedented scientific innovations and technological progress, which opens up new opportunities for solving these problems. He also called for joint efforts to use this innovative force and find effective solutions to eliminate complex risks [Cassis, 2019]. 


\section{International cooperation}

The space has never been as important as it is now. Space information technologies are of significance not only in space exploration but also for improving the life quality on the Earth. Many people around the world use the space-provided services every day without realizing it. No one can dispute the thesis that "the space is different from the space as it was 60 years ago". J. J. Dordain correctly noted the transition from the "demonstrative role" to the fact that space became serving the population, from the "cold war" to peace, from competition to cooperation, from space to Earth, from two space-faring nations to their variety in his statement devoted to the 50th anniversary of space exploration [Dordain, 2009: 18].

Therefore, international cooperation today is extremely relevant in the use of space information technologies for sustainable development and disaster management.

The legal regulation of international cooperation on using space technologies for disaster management is based on the United Nations General Assembly Resolution 41/65 of 03/12/1986. This document fixes 15 principles of remote sensing of the Earth, some of which set up the 'game rules' in this area. Principles II, X and XI provide for the Earth remote sensing activities for the benefit and in the interests of all countries, calling for promoting the protection of the Earth's natural environment and mankind from natural disasters by cooperating and sharing relevant information. Further, according to principles V-VII and IX, all countries, both carrying out sensing activities and participating in sensing activities, are called for international cooperation [A/RES/41/65, 1986].

It is regrettable that it is sometimes hard to predict a disaster in advance. Therefore, specific attention should be paid to develop international cooperation on emergency response and assistance in an emergency, search and rescue operations. These tasks are often complicated due to the lack of communication as disasters destroy the ground communications infrastructure necessary to coordinate relief efforts, effectively provide humanitarian aid and share accurate information about the disaster to people at risk. The solution to this problem became possible by using the satellite telecommunications systems. In this regard, the Tampere Convention on the Provision of Telecommunication Resources for Disaster Mitigation and Relief Operations [Tampere, 1998] was adopted in 1998 (entered into force in January 2005). Its main purpose is to quickly and efficiently deploy ground-based and satellite telecommunications equipment to collect, exchange and distribute information on natural disasters among the affected population; the use of telecommunications systems, rescue services, organizations for providing humanitarian aid, etc.

The International Conference UNISPACE III of 1999 in Vienna became a place for discussing the importance of space research for the safety, development and welfare of mankind, as well as creating a global disaster prevention and mitigation system based on the use of space technology. Thus, the Conference initiated the adoption of the Charter on Cooperation in Achieving the Coordinated Use of Space Facilities in the Event of Natural Disasters or Technological Disasters, also referred to as the International Charter on Space and Major Disasters (hereinafter - the Charter) [Charter, 2000], on 25th April 2000. This Charter is an international non-governmental agreement aimed at "supply of data from satellites of the Charter's participants to states or communities whose population, activities or property are exposed to an imminent risk, or are already victims, of natural or technological disasters" (Article II of the Charter). The parties to the Charter are the largest space agencies and space systems' operators cooperating on a voluntary basis without exchanging any financial 
resources. The administrative, operational and technical coordination is provided by a Board and an executive Secretariat (Article III of the Charter).

In order to offer greater access for all countries to accurate and timely information obtained using space technology, the UN General Assembly in 2006 established the United Nations Platform for Space-based Information for Disaster Management and Emergency Response (UN-SPIDER), which is one of the programs of the UN Office for Outer Space Affairs and reports to the UN Committee on the Peaceful Uses of Outer Space. The Platform's purpose is to provide universal access to all countries and all relevant international and regional organizations to all types of space-based information and services relevant to the disaster management (paragraph 6 of UNGA Resolution 61/110) [A/RES/61/110, 2006]. UN-SPIDER functions as a center for the transfer of space-based information, a link between the various communities responsible for disaster prevention and response.

The UN-SPIDER Program actively interacts with a number of leading global and regional initiatives, including the abovementioned International Charter on Space and Major Disasters (the United Nations Office for Outer Space Affairs has been a collaborating body of the Charter since 2003). Also, to quickly collect data, the Program cooperates with many space agencies and private sector organizations engaged in space activities. UN-SPIDER is actively engaged in providing advisory and technical support to many countries, helping to strengthen national capacities in disaster risk reduction and prevention through space technology. The effectiveness of emergency response measures implemented by the Platform is steadily increasing.

The analysis of the world experience in the monitoring systems' set up has shown that the leaders among the developed countries are the United States and the EU monitoring the dangerous phenomena, processes, factors with the obligatory placement of controls on space platforms and sending the received information to ground monitoring centers. Among the best examples of such systems are the Copernicus Emergency Management Service (Copernicus EMS), Pachube (Japan) etc.

Most countries do not have their own artificial satellites which increases the importance international cooperation on the use of space information technology. For example, Ukraine has space carriers, but does not have its own artificial Earth satellites to host Earth remote sensing facilities.

Therefore, it is very important and productive that Ukraine has already begun to engage with the number of international initiatives aimed at using Earth remote sensing data for prevention, emergency recovery and response. These include the Global Earth Observation System of Systems (GEOSS), the Global Charter on Space and Major Disasters, the Partnership for an Integrated Global Observation Strategy, Global Monitoring for Environmental Security (GMES), the Natural Disaster Prevention and Mitigation Programme of the World Meteorological Organization, the UN-SPIDER Platform and the International Charter "Space and Major Disasters".

Being aware of the importance of disasters and space information technologies global governance for the community sustainable development, the Committee on the Peaceful Uses of Outer Space adopted a strategic document — the draft agenda "Space-2030" (together with its implementation plan) at its sixty-second session, which was held in Vienna from 12 to 21 June 2019. This document was presented by the General Assembly Committee as a comprehensive and forward-looking strategy for consolidating and strengthening the contribution of space activities and technologies to the global programs' implementation and ensuring long-term sustainable development for the benefit of all mankind [A/AC.105/L.317, 2019]. 
Upon considering the information obtained during the International Conference UNISPACE+50, the Committee formulated the following seven thematic priorities in the space technology use for sustainable development:

- global partnership in space exploration and innovation;

- legal regime of outer space and global space governance;

- enhanced information exchange on space objects and events;

- international framework for space weather services;

- strengthened space cooperation for global health;

- international cooperation towards low-emission and resilient societies;

- capacity-building for the twenty-first century [A/RES/73/6, 2018].

The above international initiatives clearly demonstrate the active development of international cooperation on prevention, response to disasters and managing their consequences using the space technologies. However, this cooperation is carried out on a voluntary basis. As noted, space meteorology, telecommunications and remote sensing activities play an extremely important role in helping to prevent and eliminate emergencies. Effective implementation of these types of space activities requires a clear legal regulation.

\section{Conclusions}

In recent years, the role of cosmonautics has undergone significant changes in relation to its impact on the scientific and technical level and, ultimately, on the competitiveness of the economy. Analysts mention a change in the paradigm of modern space activities expressing itself in the shifting from strategic pursuit in the name of leadership to the priority of sustainable development and consumer orientation. The effectiveness of space programs is not measured by the number of launches, but by the answers to the questions: how will the security of the country and the region increase, what are the benefits from disaster forecasting or assessment, how to improve specific management decisions? Therefore, the thesis that the country is a "space country" now requires different argumentation than it was twenty years ago.

1. Space technologies play an important role in minimizing the negative impact of natural disasters. Satellite imagery providing real-time information in a vast area and space technologies such as telecommunications, global navigation satellite systems, geographic information systems and web technologies can be used to prevent, prepare to, assist, rehabilitate, alert and monitor on various stages of the disaster management.

2. Without a global, integrated and coordinated approach based on the experience gained from existing international initiatives, there will still be a significant backlog in the use of space information technology for the prevention and mitigation of emergencies in most parts of the world.

3. Relations arising in this area are not regulated comprehensively. These is a need to create an international legal mechanism regulating all aspects of the use of space information technology (Earth remote sensing systems, satellite systems of meteorology, navigation and telecommunications) for prevention and managing the disasters, clearly defining the rights and obligations of "providers" and "recipients" of data space exploration. The further development of international law should be aimed at solving this task, and this is possible only by joint efforts of all states.

Thus, disaster management through space information technology for system resilience is a set of all available international mechanisms (legal, technical, organizational) to ensure 
the system's ability to anticipate, control adverse effects and consequences, adapt and achieve disaster-response.

\section{References}

A/RES/41/65. Resolution of UN General Assembly. Principles relating to remote sensing of the Earth from the outer space, 3 December 1986 . https://undocs.org/en/A/RES/41/65

A/RES/56/195 Resolution adopted by the General Assembly [on the report of the Second Committee (A/56/561/Add.2)] 56/195. International Strategy for Disaster Reduction, 2002. https://www.un.org/en/ga/search/view_doc.asp?symbol=A/RES/56/195

A/RES/61/110. Resolution adopted by the General Assembly 61/110. United Nations Platform for Space-based Information for Disaster Management and Emergency Response, on 14 December 2006. https://undocs.org/en/A/RES/61/110

A/RES/73/6. Resolution adopted by the General Assembly 73/6. Fiftieth anniversary of the first United Nations Conference on the Exploration and Peaceful Uses of Outer Space: space as a driver of sustainable development, on 26 October 2018. https://undocs.org/ en $/ \mathrm{a} / \mathrm{res} / 73 / 6$

A/AC.105/L.317. Committee on the Peaceful Uses of Outer Space Sixty-second session. Zero draft of the "Space2030" Agenda and implementation plan, 2019. http://www.unoosa. org/res/oosadoc/data/documents/2019/aac_1051/aac_1051_317_0_html/V1903343.pdf

Besekersky V.A., Popov E.P. The theory of automatic control systems. M .: Science, 1972 $768 \mathrm{p}$.

Charter on Cooperation to Achieve the Coordinated Use of Space Facilities in the Event of Natural or Technological Disasters, 25 April 2000, Rev.3 (25/4/2000).2. https://www. refworld.org/docid/41de7e544.html

Dowell, Mark. et. al. Strategy Towards an Architecture for Climate Monitoring from Space, 2013. http://www.wmo.int/pages/prog/sat/documents/ARCH_strategy-climatearchitecture-space.pdf

Dordain, J.-J. Statement by the Director General of the European Space Agency. Fifty years of space exploration. According to the materials of the International Forum dedicated to the 50th anniversary of the launch of the First artificial Earth satellite, "Cosmos: Science and Problems XXI", October 2007. Russian Academy of Sciences, Moscow / Ed. A.V. Zakharov. - M .: FIZMATLIT, 2009. - 280 p. https://books. google.com.ua/books?id=fGktDAAAQBAJ\&dq=\%D0\%BA $\%$ D0 $\%$ BE $\%$ D $1 \% 81 \%$ D $0 \%$ BC $\%$ D0 $\%$ BE $\%$ D $1 \% 81+\%$ D $\%$ B $8+\%$ D $1 \% 83 \%$ D0 $\%$ BF $\%$ D $1 \% 80 \%$ D0 $\%$ B0 $\%$ D0 $\%$ B2 $\%$ D0 $\%$ BB $\%$ D0 $\%$ B5\%D0\%BD $\%$ D0 $\%$ B $8 \%$ D0 $\%$ B5+\%D $1 \% 81 \%$ D 1 $\% 82 \%$ D0\%B8\%D1\%85\%D0\%B8\%D0\%B9\%D0\%BD $\%$ D $1 \% 8$ B $\%$ D0 $\%$ BC $\%$ D0 $\%$ B8+\%D0\%B1\%D0\%B5\%D0\%B4\%D1\%81\%D1\%82\%D0\%B2\%D0\%B8\%D1\%8F $\% \mathrm{D} 0 \% \mathrm{BC} \% \mathrm{D} 0 \% \mathrm{~B} 8 \& \mathrm{hl}=\mathrm{ru} \&$ source $=\mathrm{gbs} \_$navlinks_s

Cassis, Ignacio H. E. The Benefits of Resilience: Towards a Sustainable and Open Society. Programme GP2019. 13 - 17 May 2019 - Geneva, Switzerland https://www. preventionweb.net/files/58809_programmedefopeningtimeupdated[1].pdf

Hyogo Framework for Action 2005-2015: I S D R International Strategy for Disaster Reduction International Strategy for Disaster Reduction, 2005. https://www.unisdr.org/2005/wcdr/ intergover/official-doc/L-docs/Hyogo-framework-for-action-english.pdf 
Methodological foundations of financial management: monograph/resp. ed. N.D. SchimshirtTomsk: Publishing house of Tomsk State University, 2013. - 330 p.

Martin, Ron, Peter Sunley. On the notion of regional economic resilience: conceptualization and explanation. Journal of Economic Geography, Volume 15, Issue 1, January 2015, Pages 1-42, https://doi.org/10.1093/jeg/lbu015

Rodin, Judith. The Resilience Dividend: Managing disruption, avoiding disaster, and growing stronger in an unpredictable world, 2014. https://books.google.com.ua/books/about/ The_Resilience_Dividend.html?id=rO9YBQAAQBAJ\&redir_esc $=\mathrm{y}$

Subbarao A., Priya R and KrunalJ Joshi. SPACE TECHNOLOGY IN DISASTER MANAGEMENT. ResearchGate, January 2014 http://www.orissabigyanacademy.nic. in/pdf/S_H_January_2014.pdf\#page=20

Sendai Framework for Disaster Risk Reduction for 2015-2030, 2015. https://www.unisdr.org/ files/43291_sendaiframeworkfordrren.pdf

Tampere Convention on the Provision of Telecommunication. Resources for Disaster Mitigation and Relief Operations, 18 June 1998. https://treaties.un.org/pages/ViewDetails. aspx?src=TREATY\&mtdsg_no $=X X V-4 \&$ chapter $=25 \&$ clang $=\_$en 